\title{
Timing and Circumstances of First Sex among Female and Male Youth from Select Urban Areas of Nigeria, Kenya, and Senegal
}

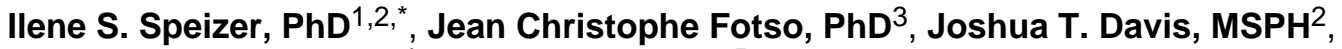 \\ Abdulmumin Saad, $\mathbf{P h D}^{4}$, and Jane Otai, $\mathbf{M A}^{5}$ \\ ${ }^{1}$ Department of Maternal \& Child Health, Gillings School of Global Public Health, The University \\ of North Carolina at Chapel Hill, Chapel Hill, NC 27599, USA \\ ${ }^{2}$ Carolina Population Center at The University of North Carolina at Chapel Hill, Chapel Hill, NC \\ 27599, USA \\ ${ }^{3}$ Independent Consultant, Johns Hopkins University Center for Communications Programs, \\ Abuja, Nigeria \\ ${ }^{4}$ Nigerian Urban Reproductive Health Initiative (NURHI), Johns Hopkins University Center for \\ Communications Programs, Abuja, Nigeria \\ ${ }^{5}$ Tupange Project, Jhpiego, an affiliate of Johns Hopkins University, Nairobi, Kenya
}

\begin{abstract}
Purpose-To examine the timing and circumstances of first sex among urban female and male youth in Kenya, Nigeria, and Senegal.
\end{abstract}

Methods-Recently collected data are used to examine youth sexual behaviors in Kenya, Nigeria, and Senegal. In each country, a large, representative sample of women (ages 15-49) and men (ages 15-59) was collected from multiple cities. Data from youth (ages 15-24) are used for the analyses of age at sexual initiation, whether first sex was premarital, and modern family planning use at first sex. Cox proportional hazard models and logistic regression analyses are performed to determine factors associated with these outcomes.

Results-Across all three countries, a greater percentage of male youth than female youth report initiating sex with a non-marital partner. More educated youth are less likely to have initiated sex at each age. In Nigeria and Senegal, poor female youth report earlier first sex than wealthier female youth. In Kenya, richer female youth are more likely to have premarital first sex and to use contraception/condom at first sex than their poorer counterparts. Older age at first sex and youth who report that first sex was premarital are significantly more likely to use a method of contraception (including condom) at first sex. City specific distinctions are found and discussed for each outcome.

Conclusion-Programs seeking to reduce HIV and unintended pregnancy risk among urban youth need to undertake needs assessments to understand the local context that influences the timing and circumstances of first sex in each city/country-specific context.

(C) 2013 Society for Adolescent Medicine. Published by Elsevier Inc. All rights reserved.

*Corresponding Author: Ilene S. Speizer, Department of Maternal and Child Health, Gillings School of Global Public Health, University of North Carolina at Chapel Hill, 206 W. Franklin St., CB 8120, Chapel Hill, NC 27516, Tel: 919-966-7411, Fax: 919-966-2391, ilene_speizer@unc.edu.

Publisher's Disclaimer: This is a PDF file of an unedited manuscript that has been accepted for publication. As a service to our customers we are providing this early version of the manuscript. The manuscript will undergo copyediting, typesetting, and review of the resulting proof before it is published in its final citable form. Please note that during the production process errors may be discovered which could affect the content, and all legal disclaimers that apply to the journal pertain. 


\section{Keywords}

Sexual Initiation; Premarital Sex; Condom Use; Kenya; Nigeria; Senegal; Urban

\section{Introduction}

Increasingly, young people (ages 15-24) are moving to urban areas for improved education and employment opportunities [1]; understanding their sexual and reproductive health behaviors is important for designing programs to improve attainment of education and employment goals. Sexual debut is an important transition in a young person's life as it is the beginning of his/her exposure to the risk of pregnancy (planned and unplanned) and sexually transmitted infections, (STI) including human immunodeficiency virus (HIV) [29]. Recent studies demonstrate that earlier sexual debut is associated with more lifetime sexual partners and greater risks of STI/HIV [10-13]. For women, initiation of sexual activity is closely tied to marriage and childbearing; however, more educated women are better able to delay sexual debut and dissociate sexual initiation, marriage, and childbearing $[12,14,15]$. Young men's sexual and reproductive behaviors are less closely tied; a greater percentage have non-marital first sex and tend to have a long period between first sex, marriage, and subsequent procreation $[1,12,16]$.

Recent national-level studies from sub-Saharan Africa have demonstrated declines in early sex (sex before age 15) [1] and concomitant declines in teenage pregnancies [17]. Notably, use of contraception or condoms at first and recent sex among young people remains low $[1,17]$. Studies comparing urban and rural youth demonstrate that a greater percentage of rural youth have early sex, are married, and have initiated childbearing, whereas a greater percentage of urban youth engage in premarital sex, have sex with multiple partners, and use modern contraception [4,6-8,18-22]. Educated and wealthier youth, who tend to be concentrated in urban areas, have similar behaviors to urban dwellers $[4,7,8,15,16,21,23,24]$.

With the dissociation of sexual initiation, marriage, and childbearing, there is a need to more closely examine which factors influence risk of unintended pregnancy, abortion, STI, and HIV among urban youth. Recent studies demonstrate that, compared to females, males are more likely to engage in early and premarital sex [25-28]. Moreover in urban settings, higher education and current enrollment in school are protective against early sex [27,29]; however higher education is associated with having multiple sexual partners [30]. Finally, residents of slums or disadvantaged environments are more likely to engage in early and unprotected sex $[27,31,32]$. While these studies provide important insights into youth sexual behaviors, they are mostly limited to the unmarried, to youth in one specific city $[26,27,29-$ $31]$ and to Demographic and Health Survey data that has small sample sizes for urban areas [28].

Large, representative samples of urban youth are needed to allow for more refined analyses of education and wealth effects. In this study, we use recently collected data to examine the timing and circumstances of first sex among female and male youth from select major urban areas in Kenya, Nigeria, and Senegal. This study answers the following research question: How similar or different are factors associated with the timing and circumstances of first sex among female and male youth? We hypothesize that young people having premarital first sex will be more likely to use contraception than young people having marital first sex. We also hypothesize that education and wealth will be associated with sexual experience, premarital first sex, and contraceptive use at first sex, however, the effects may differ between female and male youth and across the countries. 


\section{Methods}

In 2009, the Bill \& Melinda Gates Foundation initiated a program to increase contraceptive use in urban areas in four countries: India (Uttar Pradesh), Kenya, Nigeria, and Senegal. This study uses baseline data collected by the Measurement, Learning \& Evaluation (MLE) project to evaluate the Urban Reproductive Health Initiative (URHI) in the three African countries. ${ }^{1}$ In each study country, MLE collected baseline data from a representative sample of women ages 15-49 and men ages 15-59 in program cities selected by the implementing partner and donor. In Kenya, three cities are included: Nairobi, Kisumu, and Mombasa; in Nigeria, the four cities are: Abuja, Ibadan, Ilorin, and Kaduna; and in Senegal the four cities are: Dakar, Pikine, Guédiawaye, and Mbao. (See baseline reports at www.urbanreproductivehealth.org for details of data collection and cities.)

A similar two-stage sampling design was used in each country. In Kenya, the 2009 national census frame was used to determine whether each primary sampling unit (PSU) was informal (no land tenure/slum) or formal (has land tenure/non-slum). In Senegal, municipal leaders were asked to classify neighborhoods as poor or non-poor based on characteristics of the majority of the households in the neighborhood; United Nations Habitat criteria on five housing conditions were used (type of housing; residential security; neighborhood density; access to water; and access to flush toilets). Classified neighborhoods were linked to the census sampling frame prior to selection. In Nigeria, there was no way to distinguish a PSU as poor or non-poor prior to (or after) selection; therefore the 2006 census sampling frame was used. For each city (within each country), a representative sample of PSUs was selected. Where stratification by slum/non-slum was possible, half of the selected PSUs were from each stratum. In the second stage of selection, a random sample of households was selected (30 per PSU in Kenya, 41 in Nigeria, and 21 in Senegal) based on the listing and mapping conducted in the selected PSU. In all selected households, all women (ages 15-49) who spent the previous night in the household were eligible for interview. In half of the selected households, all men ages 15-59 who spent the previous night were interviewed. All study methods were approved by the Institutional Review Board (IRB) at the University of North Carolina in Chapel Hill and by in-country IRBs in Kenya, Nigeria, and Senegal.

This analysis includes 15-24 year old female and male respondents as is typically done in youth studies; this resulted in a sample of between $30-40 \%$ of the full study sample in each country. See Table 1 for weighted sample sizes by sex and country.

The first outcome variable is age at sexual debut. For youth who never had sex, the age at the time of survey was considered in the survival analysis. The second outcome, derived from age at first sex and age at first marriage, is whether first sex was premarital (coded one) or not (coded zero). When the ages were the same, we coded first sex as in union; this is the conservative approach. Finally, we examine modern method use at first sex which is coded one if the woman (or man) reported using pill, intrauterine device, injections, male condom, implant, emergency contraception, spermicides, or female condom at first sex and coded zero if no modern method was used.

All analyses control for education, employment status, duration of residence, religion, and whether living in a slum/non-slum site (not available for Nigeria). See Table 1 for descriptive characteristics and classifications of these variables. Analyses also control for wealth quintiles calculated across the cities within countries using household assets similar to the Demographic and Health Surveys [33]. In each country, analyses control for city variables; for standardization, the capital city was selected as the reference group.

\footnotetext{
${ }^{1}$ India data were not included since the sample only included married women.
} 
Descriptive statistics are presented to demonstrate differences across the countries and for female and male youth. Kaplan-Meier survival curves of age at first sex for persons under age 35 are presented to provide a descriptive perspective of the transition to sexual experience among female and male youth and across countries. Multivariate analyses stratified by sex and country examine which factors are associated with the outcomes and similarities and differences between female and male youth and across countries. Cox proportional hazards regression is used for the analysis of age at sexual debut. Multivariate logistic regression analyses are presented for whether first sex was premarital and whether modern contraception was used at first sex. Descriptive, sex-specific tabulations are weighted based on probability of selection and response rates whereas the survival curves and multivariate analyses are not weighted; multivariate models control for the countryspecific clustered survey design using Stata version 12.

\section{Results}

Table 1 shows that across the three countries, compared to females, a greater percentage of male youth are educated, working, single, and have always lived in their current place of residence. The main distinction across the countries is that the Kenya sample is older; this may reflect greater attendance of boarding schools for 15-19 year olds in Kenya making this group less accessible at the time of the survey. There are also religious distinctions across the samples: in Senegal, the overwhelming majority of respondents are Muslim, compared to about $50 \%$ in Nigeria and only $13-14 \%$ in Kenya where the majority of the sample is Protestant.

Figure 1 presents Kaplan-Meier survival curves for transition to first sex. Male youth from Nigeria and Senegal have nearly identical curves indicating a similar transition to first sexual experience in these two settings. Conversely, the curve for Kenyan male youth is below the curve for the other two countries indicating greater sexual experience at each age. Also presented are transition to first sex curves among female youth: transition to first premarital sex and transition to first marital sex. Transition to premarital first sex is more common among Kenyan youth followed by Nigerian youth. Female youth from Senegal who have premarital first sex do so at later ages. In Senegal, female youth transition to marital first sex at a younger age than their counterparts in Kenya and Nigeria. The survival curves in the three countries are more similar for marital than for premarital first sex.

The bottom of Table 1 shows that a greater percentage of Kenyan youth are sexually experienced. Three-quarters of Kenyan female youth report that their first sex was premarital whereas in Nigeria about two-thirds and in Senegal about one-third report the same. The overwhelming majority of male youth report that their first sex was premarital (> 95\%). Among sexually experienced females, about 16-17\% in Kenya and Nigeria report using a modern method of contraception at first sex, compared to only 8\% in Senegal. Among males, the percentage reporting use of modern contraception at first sex is higher in all three countries, with the reported use highest in Senegal (33\%). Notably, the overwhelming majority of females and males reported the method they used at first sex was condom use (not shown).

Table 2 presents the Cox regression hazard ratios and $95 \%$ confidence intervals for age at sexual debut among female and male youth by country. Across all three countries, more educated female youth and female youth working or in school are significantly less likely to have initiated sex at each age than their less educated or unemployed counterparts. In Nigeria and Senegal, poorer female youth are more likely to have initiated sex at each age than their richer counterparts; this effect was not significant in Kenya. In Nigeria and Senegal, youth who moved in the last one year or sooner are significantly more likely to 
have initiated sex at each age than those who always lived in their current place of residence. This may reflect young people (mostly women) moving at the time of marriage (and thus sexual initiation). Furthermore, Muslim female youth in Nigeria are significantly more likely to have initiated sex at each age than non-Muslim female youth; this may reflect younger age at marriage among Muslim youth [24]. In Kenya, Catholic female youth are more likely to report sex at each age than Protestant youth. In Kenya, female youth from Kisumu are significantly more likely to have initiated sex at each age as compared to female youth from Nairobi.

The effects for male youth were less consistent. Kenyan males with more education were less likely to report sexual initiation at each age. Conversely in Senegal, more educated males were more likely to report having initiated sex at each age. In Nigeria, important distinctions were observed by city of residence. Males from Ibadan and Ilorin were significantly more likely to report sexual initiation at a younger age than males from Abuja. However, Kaduna males were significantly less likely to report having initiated sex at each age than males from Abuja.

Table 3 presents the logistic regression odds ratios and 95\% confidence intervals for whether female youth report that first sex was premarital. Male youth are not included since the overwhelming majority had premarital first sex. In all three countries, older age at sexual debut is associated with a lower likelihood that first sex was premarital. The effect of education on whether or not first sex is premarital is consistent across all countries; females with more education are significantly more likely to report first sex as premarital. Furthermore, Muslims are less likely to report first sex as premarital than non-Muslims. Those who moved recently in Kenya and Nigeria are less likely to have had premarital first sex, which may correspond to marriage followed by a move. Only in Kenya does wealth matter: the richest youth are significantly more likely to report premarital first sex. Likewise, slum dwellers in Kenya are less likely to have had premarital first sex. Current employment was only significant in Senegal; unemployed females are more likely to report first sex as premarital. Further examination of city-level effects reveals important distinctions. Compared to Abuja, respondents from Ibadan and Ilorin are significantly more likely to report premarital first sex, whereas females from Kaduna are less likely to report the same. In Senegal, females from Pikine and Mbao are less likely to report premarital first sex than females from Dakar.

Table 4 presents the logistic regression odds ratios and 95\% confidence intervals for the analysis of whether modern contraception was used at first sex. In all three countries, male youth who were older at first sex are significantly more likely to have used contraception at first sex, a finding which was only significant among female youth in Kenya. In all three countries, female youth who reported first sex as premarital are significantly more likely to report using a modern method at first sex, For men, premarital first sex was significant in Nigeria and Kenya. More educated youth, both female and male, were significantly more likely to have used modern contraception at first sex. Religion is important in Senegal and Nigeria, with Muslim females less likely to use a method at first sex; the same finding was shown for males in Nigeria. Again, wealth is only a factor among females in Kenya where the richest are significantly more likely to have used modern contraception at first sex. There are important city-level differences in Kenya and Nigeria. Compared to those from Abuja, female youth from Kaduna are less likely to use a method at first sex; this finding held for men in Kaduna and Ilorin. In Kenya, youth from Kisumu are significantly more likely to report using a modern method at first sex than youth from Nairobi. 


\section{Discussion}

This study uses novel data from representative samples in Kenya, Nigeria and Senegal to provide important insights into the sexual initiation of urban female and male youth. A number of consistent results were found across the countries that are worth noting. First, as found in other youth studies [12,15], more educated urban female youth engage in first sex later. Educated youth were also more likely to have premarital first sex; however, this is more likely to be protected through contraception/condom use. Greater premarital sex among the educated may represent the tension between delaying marriage and social/peer pressures to initiate sex, especially in university environments [14]. Furthermore, in all three countries, women who were not working or in school were more likely to report having sex at each age than those who were working/in school. This may reflect pressure to marry among women who are unemployed or out of school. Consistent across the countries was that Muslim women were less likely to report first sex as premarital compared to others. Women who initiate sex at an older age are more likely to have marital rather than premarital first sex. Further, women having premarital first sex are significantly more likely to use a modern contraceptive than those who have marital first sex. Overall, contraception and condom use at first sex was low across the ages and countries; this is consistent with other urban studies $[4,6,18,20,21,25]$.

Among male youth, the findings were less consistent. Male youth who were older at first sex were more likely to use contraception/condoms. Notably, the overwhelming majority of male first sex is premarital and thus condoms and contraception are important for protection from an unplanned pregnancy and a STI/HIV.

We also found country-specific and city-specific distinctions that are important to recognize for program planning. In Kenya, richer sexually experienced female youth are more likely to have had premarital first sex and more likely to have used modern contraception at first sex than their poorer counterparts. Kisumu youth had sex at an earlier age but were also more likely to have protected first sex; this likely reflects more active HIV prevention activities in Kisumu where HIV prevalence is the highest in the country [35]. In Nigeria, the main citylevel distinctions observed for females were in Kaduna where premarital sex was uncommon and use of modern contraception at first sex was low. Conversely, among females in Ibadan and Ilorin, premarital sex was significantly higher compared to Abuja, the country's capital. Males from Ibadan and Ilorin were significantly more likely and males from Kaduna were less likely to report having sex at each age as compared to males from Abuja.

Our findings on wealth and type of neighborhood (slum/non-slum) for Kenya and Senegal show similarities to other studies on sexual risk-taking behaviors among urban youth. Two earlier studies found that slum and poorer residents were at greater risk of engagement in high risk sex [31,32]. The wealth effects we observed reflect similar findings of earlier authors who found "slum residence effects". This could be because a number of the assets we used in the wealth quintiles are the same ones used to classify women as slum or nonslum in Nairobi [31] and to create the built environment in the Cape Town [32].

This study is not without limitations. First, while this study examines the circumstances of first sex, it does not speak to whether first sex was coercive. Prior work demonstrates that early first sex (i.e., under age 15) is often a consequence of coercion, which restricts young women's control over timing and method use $[9,36]$. Second, this study uses information on self-reported sexual behaviors, which may be misreported [37,38]. Training of interviewers incorporated lessons on interviewing techniques to help reduce discomfort; this increases the reliability of the data. Third, while the examination of three countries and multiple cities 
provides a rich perspective on varying contexts, with this type of multi-country approach, it is not possible to undertake in-depth analyses to explore unexpected patterns and to understand why the findings are such. Moreover, particularly in Nigeria (a large and diverse country), we cannot generalize the findings to be representative of all cities in the country nor all cities in the northern or southern regions. Further, our definition of 'urban' could differ from that of other studies. For example, in Nigeria, the DHS includes towns as small as 20,000, where we included large major urban areas. Finally, the slum variable was not available for Nigeria and was developed differently for Kenya and Senegal. The definition of slum varies cross-nationally and may even vary across cities; we were constrained to use the measures that were available to us or that were feasible to collect.

These findings provide a number of programmatic recommendations. First, given that education is protective toward early and unprotected sex, policies and programs encouraging education should be continued. That said, while educated youth are more likely to have protected first sex, there is still only a minority of youth who use contraception (specifically condoms) at first sex. Therefore, programs providing knowledge on the importance of use and guidance on where young people can obtain contraception and condoms are needed in both school and out-of-school settings. Second, inequalities exist in sexual behaviors of urban youth by wealth group. Poorer female youth in Nigeria and Senegal are engaging in earlier sex and poorer youth in Kenya are less likely to use contraception at first sex. All urban youth need to have information and access to contraception (including condoms). This could be done through outreach programs (e.g., peer educators) that go to poor neighborhoods and slums to offer information, counseling, and methods (if feasible); using young people to target their peers is a strategy that often reduces barriers to youth access and increases use of contraception/condoms [39]. Finally, city specific differences within each country indicate the importance of adjusting program strategies to different contexts. Programs should undertake country- and city-specific needs assessments to determine the specific needs of youth in each setting. This information can be used to tailor programs to better reach youth engaging in premarital and unprotected sex and support the goal of reducing unintended pregnancies, STI and HIV among youth globally.

\section{Acknowledgments}

The authors gratefully acknowledge support from the Bill \& Melinda Gates Foundation for the support of the Urban Reproductive Health Initiative (URHI) in the target countries as well as the support of the Measurement, Learning \& Evaluation project, the evaluation component of the URHI. This research was also supported by grant, 5 R24 HD050924, Carolina Population Center, awarded to the Carolina Population Center at The University of North Carolina at Chapel Hill by the Eunice Kennedy Shriver National Institute of Child Health and Human Development. An earlier version of this paper was presented at the Population Association of America Meetings in San Francisco, CA, May, 2012.

\section{References}

1. Kothari, MT.; Wang, S.; Head, SK., et al. DHS Comparative Reports No 29. Calverton, Maryland, USA: ICF International; 2012. Trends in Adolescent Reproductive and Sexual Behaviors.

2. Cleland J, Ali MM. Sexual abstinence, contraception and condom use by young African women: A secondary analysis of survey data. Lancet. 2006; 368(5949):1788-93. [PubMed: 17113428]

3. Cleland J, Ali MM, Shah I. Trends in protective behavior among single vs. married young women in sub-Saharan Africa: The big picture. Reprod Health Matters. 2006; 14(28):17-22. [PubMed: 17101418]

4. Doyle AM, Mavedzenge SN, Plummer ML, et al. The sexual behavior of adolescents in sub-Saharan Africa: Patterns and trends from national surveys. Trop Med Int Health. 2012; 17(7):796-807. [PubMed: 22594660]

5. Patton GC, Coffey C, Cappa C, et al. Health of the world's adolescents: a synthesis of internationally comparable data. Lancet. 2012; 379 (9826):1665-75. [PubMed: 22538181] 
6. Yode M, LeGrand T. Association between age at first sexual relation and some indicators of sexual behavior among adolescents. Afr J Reprod Health. 2012; 16(2):173-188. [PubMed: 22916550]

7. Fatusi AO, Blum RW. Predictors of early sexual initiation among a nationally representative sample of Nigerian adolescents. BMC Public Health. 2008; 8:136. [PubMed: 18439236]

8. Mberu BU, White MJ. Internal migration and health: Premarital sexual initiation in Nigeria. Soc Sci Med. 2011; 72:1284-1293. [PubMed: 21435767]

9. Clark S. Early marriage and HIV risks in Sub-Saharan Africa. Stud Fam Plann. 2004; 35(3):149160. [PubMed: 15511059]

10. Ghebremichael M, Larsen U, Paintsil E. Association of age at first sex with HIV-1, HSV-2, and other sexual transmitted infections among women in northern Tanzania. Sex Transm Dis. 2009; 36(9):570-576. [PubMed: 19707109]

11. Hallett TB, Lewis JJC, Lopman BA, et al. Age at first sex and HIV infection in rural Zimbabwe. Stud Fam Plann. 2007; 38(1):1-10. [PubMed: 17385378]

12. Sauvain-Dugerdil C, Gakou B, Berthé F, et al. The start of the sexual transition in Mali: Risks and opportunities. Stud Fam Plann. 2008; 39(4):263-280. [PubMed: 19248714]

13. Wand H, Ramjee G. The relationship between age of coital debut and HIV seroprevalence among women in Durban, South Africa: A cohort study. BMJ Open. 2012; 2(1)

14. Akintola O, Ngubane L, Makhaba L. 'I did it for him, not for me': An exploratory study of factors influencing sexual debut among female university students in Durban, South Africa. J Health Psychol. 2012; 17(1):143-153. [PubMed: 21672963]

15. Adamczyk A, Greif M. Education and risky sex in Africa: Unraveling the link between women's education and reproductive health behaviors in Kenya. Soc Sci Res. 2011; 40(2):654-666.

16. Marston M, Slaymaker E, Cremin I, et al. Trends in marriage and time spent single in sub-Saharan Africa: A comparative analysis of six population-based cohort studies and nine Demographic and Health Surveys. Sex Transm Infect. 2009; 85(SUPPL 1):i64-i71. [PubMed: 19307343]

17. Prata, N.; Weidert, K.; Sreenivas, A. Meeting the need: Youth and family planning in sub-Saharan Africa. Contraception. 2012. http://dx.doi.org/10.1016/j.contraception.2012.10.001

18. Obidoa CA, M'Lan CE, Schensul SL. Factors associated with HIV/AIDS sexual risk among young women aged 15-24 years in Nigeria. J Pub Health in Nigeria. 2012; 3(e15):59-64.

19. Obare, F.; Birungi, H.; Undie, C., et al. APHIA II OR Project in Kenya. Population Council; Nairobi, Kenya: 2011. Levels, trends and determinants of contraceptive use among adolescent girls in Kenya.

20. Oyediran KA, Oluwadaisi IF, Akmap T. Predictors of condom-use among young never-married males in Nigeria. J Health Population and Nutrition. 2011; 29(3):273-285.

21. Isiugo-Abanihe UC, Oyediran KA. Household socioeconomic status and sexual behavior among Nigerian female youth. African Population Studies. 2004; 19(1):81-98.

22. Zuma K, Mzolo T, Makonko E. Determinants of age at sexual debut and associated risks among South African youths. African Journal of AIDS Research. 2011; 10(3):189-194.

23. McQuestion M, Ahiadeke C, Posner J, et al. Psychosocial processes and sexual initiation among Ghanaian youth. Health Educ Behav. 2012; 39(3):268-275. [PubMed: 21617000]

24. Madise N, Zulu E, Ciera J. Is poverty a driver for risky sexual behaviour? evidence from national surveys of adolescents in four African countries. Afr J Reprod Health. 2007; 11(3):83-98. [PubMed: 20698061]

25. Katz K, Naré C. Reproductive health knowledge and use of services among young adults in Dakar Senegal. J Biosoc Sci. 2002; 34:215-231. [PubMed: 11926455]

26. Boileau C, Zunzunegui MV, Rashed S. Gender differences in unsafe sexual behavior among young people in urban Mali. AIDS Care. 2009; 21:8:1014-1024. [PubMed: 20024758]

27. Kabiru CW, Beguy D, Undie CC, et al. Transition into first sex among adolescents in slum and non-slum communities in Nairobi, Kenya. J Youth Stud. 2010; 13(4):453-471.

28. Singh S, Wulf D, Samara R, et al. Gender differences in the timing of first intercourse: data from 14 countries. Int Fam Plan Perspect. 2000; 26:21-8.

29. Luke N, Xu H, Mberu BU, et al. Migration experience and premarital sexual initiation in urban Kenya: An event history analysis. Stud Fam Plann. 2012; 43(2):115-126. [PubMed: 23175950] 
30. Tenkorang EY, Maticka-Tyndale E, Rajulton F. A multi-level analysis of risk perception, poverty and sexual risk-taking among young people in Cape Town, South Africa. Health Place. 2011; 17(2):525-535. [PubMed: 21195013]

31. Zulu EM, Dodoo FNAC, Ezeh A. Sexual risk-taking in the slums of Nairobi, Kenya, 1993-8. Popul Stud (Camb). 2002; 56(3):311-23. [PubMed: 12553329]

32. Burns PA, Snow RC. The built environment \& the impact of neighborhood characteristics on youth sexual risk behavior in Cape Town, South Africa. Health Place. 2012; 18(5):1088-1100. [PubMed: 22704913]

33. Gwatkin, DR.; Rutstein, S.; Johnson, K., et al. Socio-economic differences in health, nutrition, and population (HNP). HNP/Poverty Thematic Group, World Bank; Washington DC: 2000.

34. National Population Commission (NPC) [Nigeria] and ICF Macro. Nigeria Demographic and Health Survey 2008. Abuja, Nigeria: National Population Commission and ICF Macro; 2009.

35. Kenya National Bureau of Statistics (KNBS) and ICF Macro. Kenya Demographic and Health Survey 2008-09. Calverton, Maryland: KNBS and ICF Macro; 2010.

36. Moore AM, Awusabo-Asare K, Madise N, et al. Coerced first sex among adolescent girls in subSaharan Africa: Prevalence and context. Afr J Reprod Health. 2007; 11(3):62-82. [PubMed: 18458747]

37. Curtis SL, Sutherland EG. Measuring sexual behavior in the era of HIV/AIDS: The experience of Demographic and Health Surveys and similar enquiries. Sex Transm Infect. 2004; 80(Suppl II):ii22-ii27. [PubMed: 15572636]

38. Beguy D, Kabiru CW, Nderu EN, et al. Inconsistencies in self-reporting of sexual activity among the young people in Nairobi, Kenya. J Adolesc Health. 2009; 45:595-601. [PubMed: 19931832]

39. Speizer IS, Magnani RJ, Colvin CE. The effectiveness of adolescent reproductive health interventions in developing countries: A review of the evidence. J Adolesc Health. 2003; 33(5): 324-48. [PubMed: 14596955] 


\section{Implications and Contribution}

Novel data from Kenyan, Nigerian, and Senegalese urban youth demonstrate education and wealth distinctions in the timing and circumstances of first sex between youth from different cities in each country and across countries. Programs to prevent HIV and unintended pregnancy among urban youth should take into account observed distinctions. 

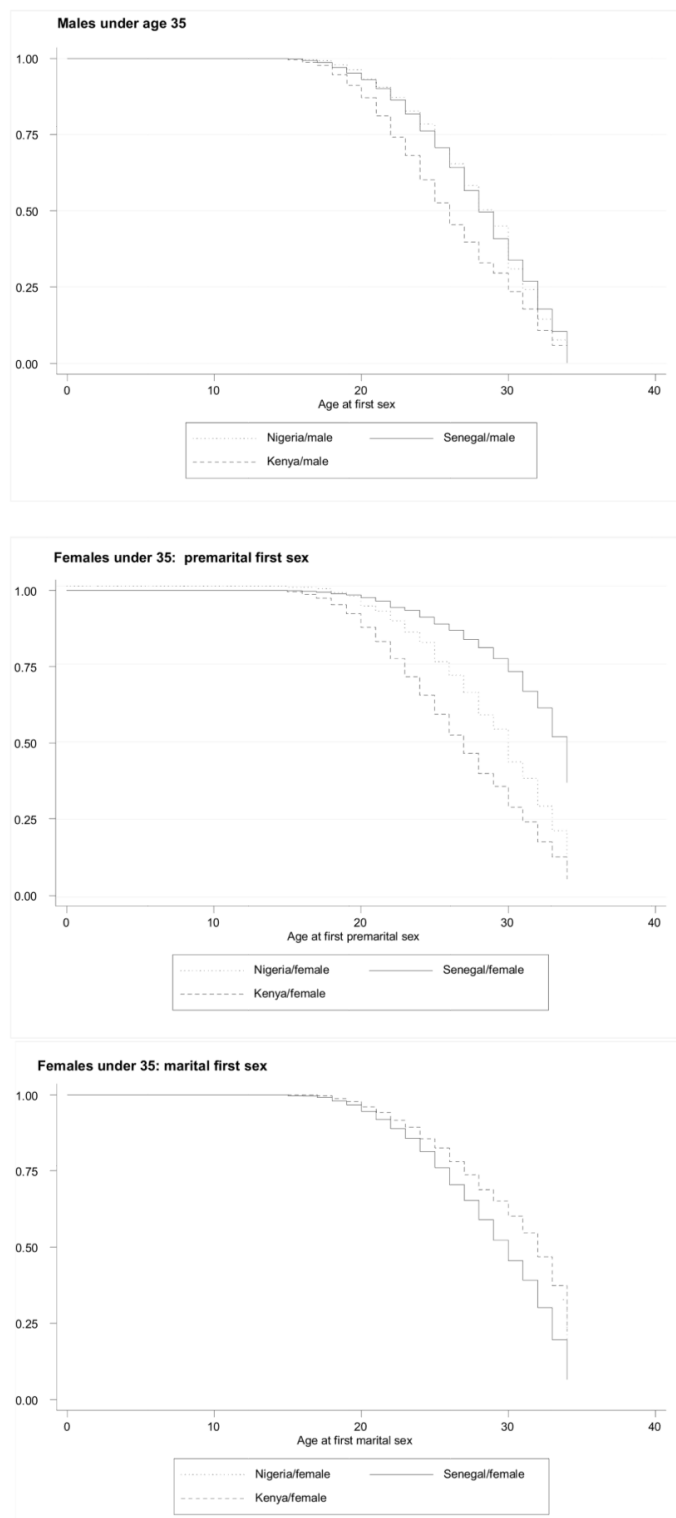

Figure 1.

Kaplan-Meier survival curves of age at first sex by country 


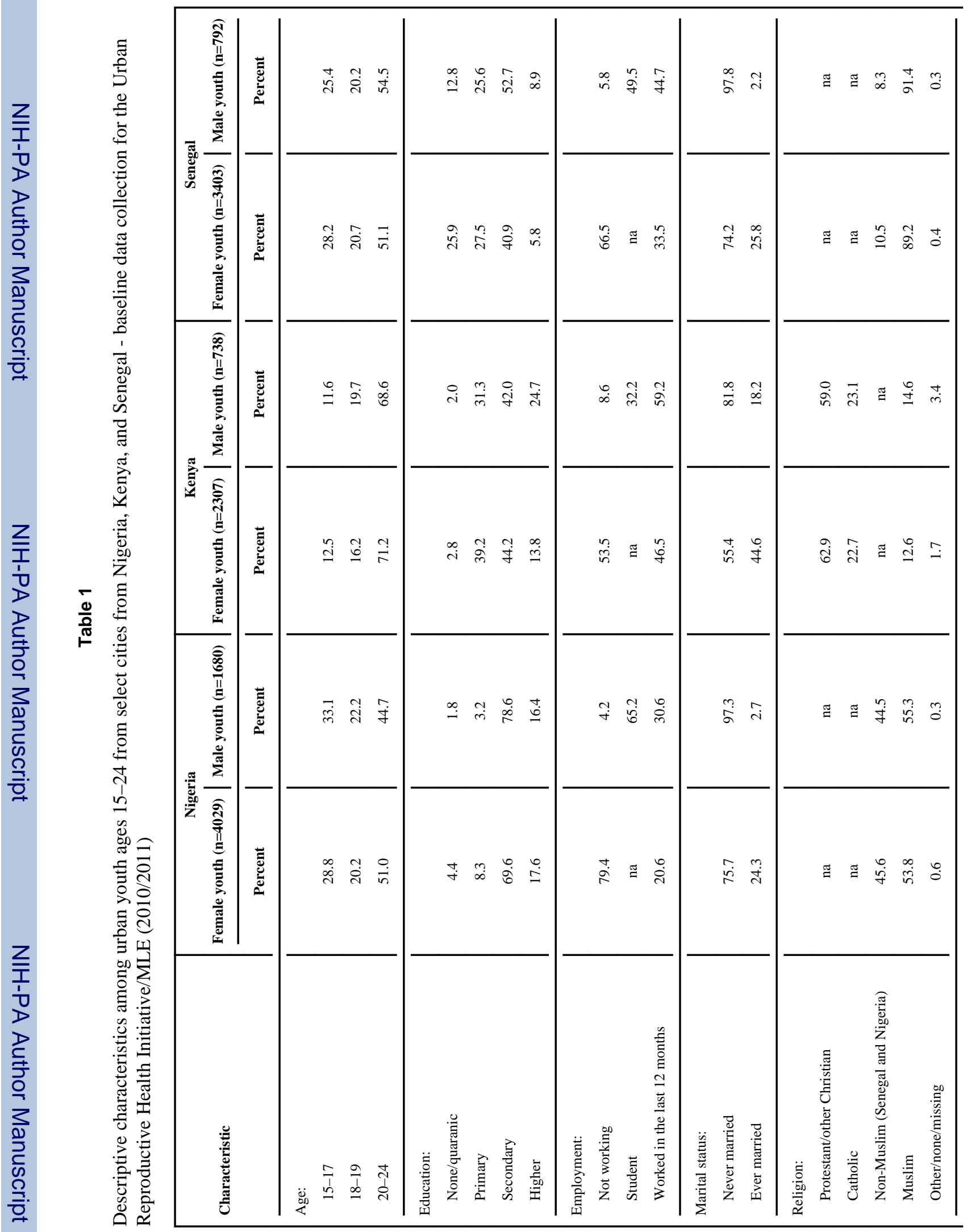




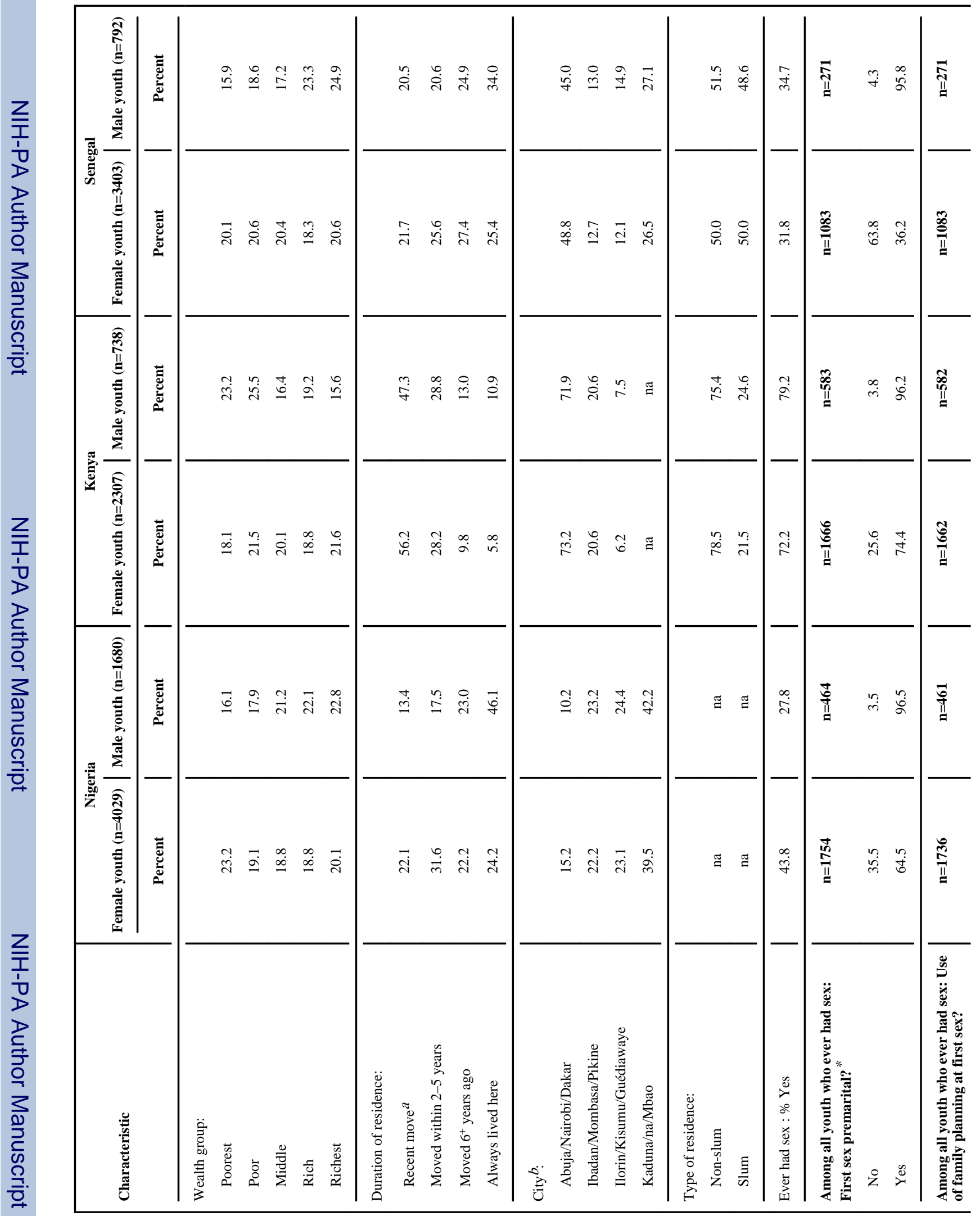




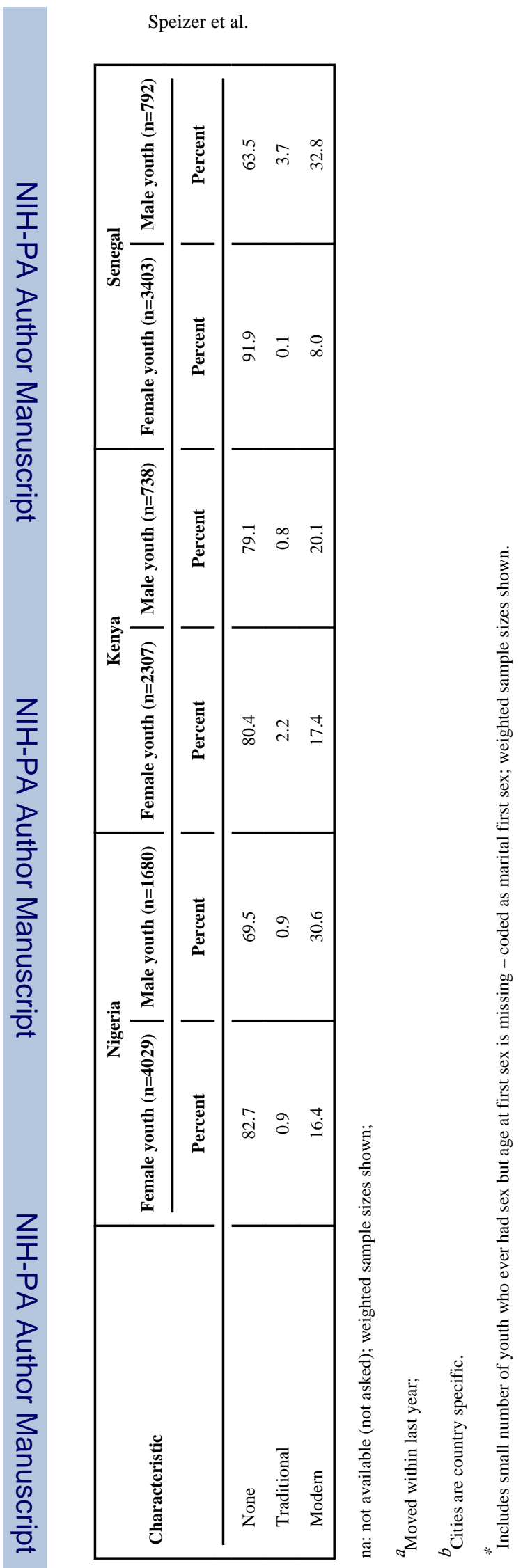

J Adolesc Health. Author manuscript; available in PMC 2014 November 01. 


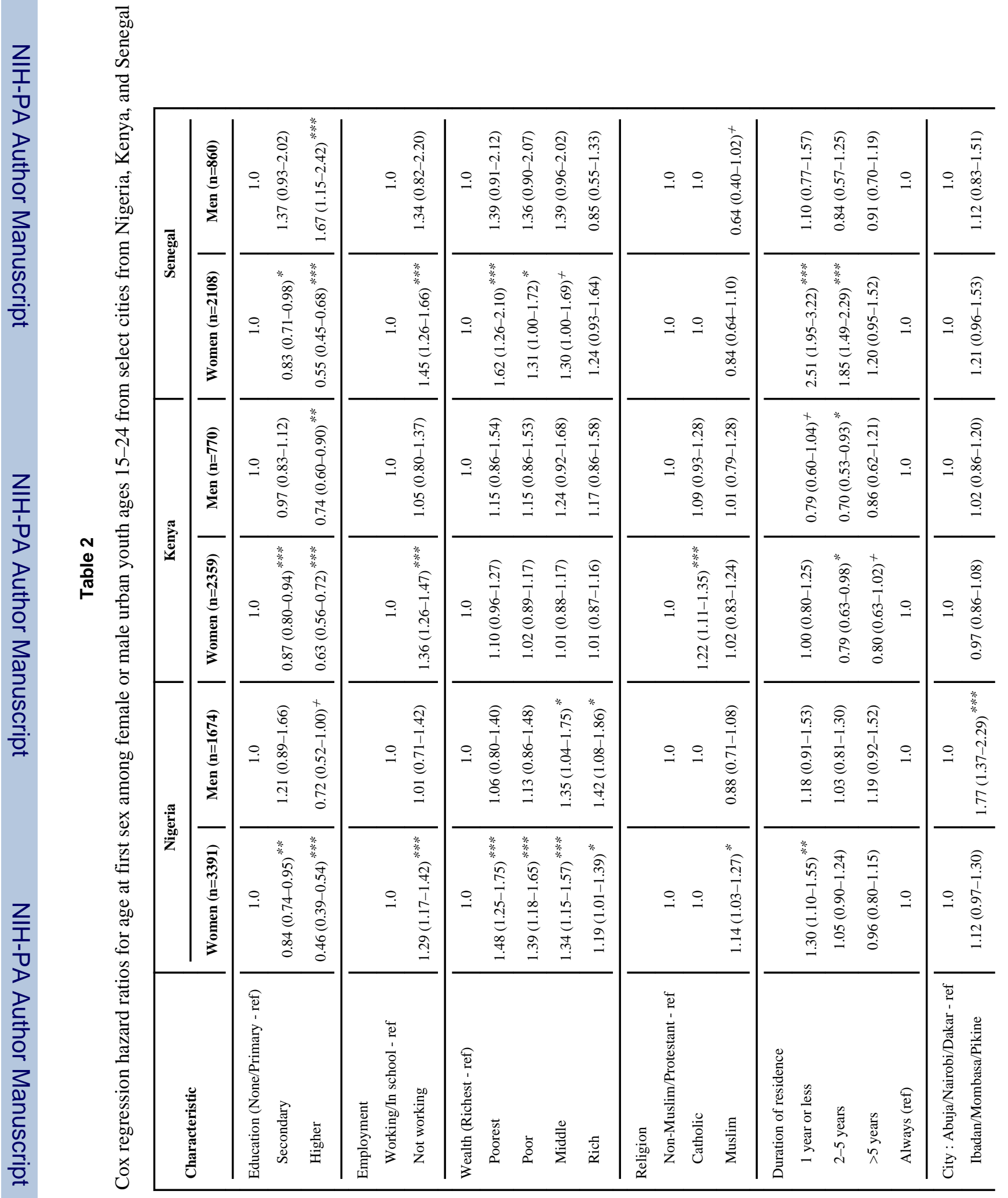




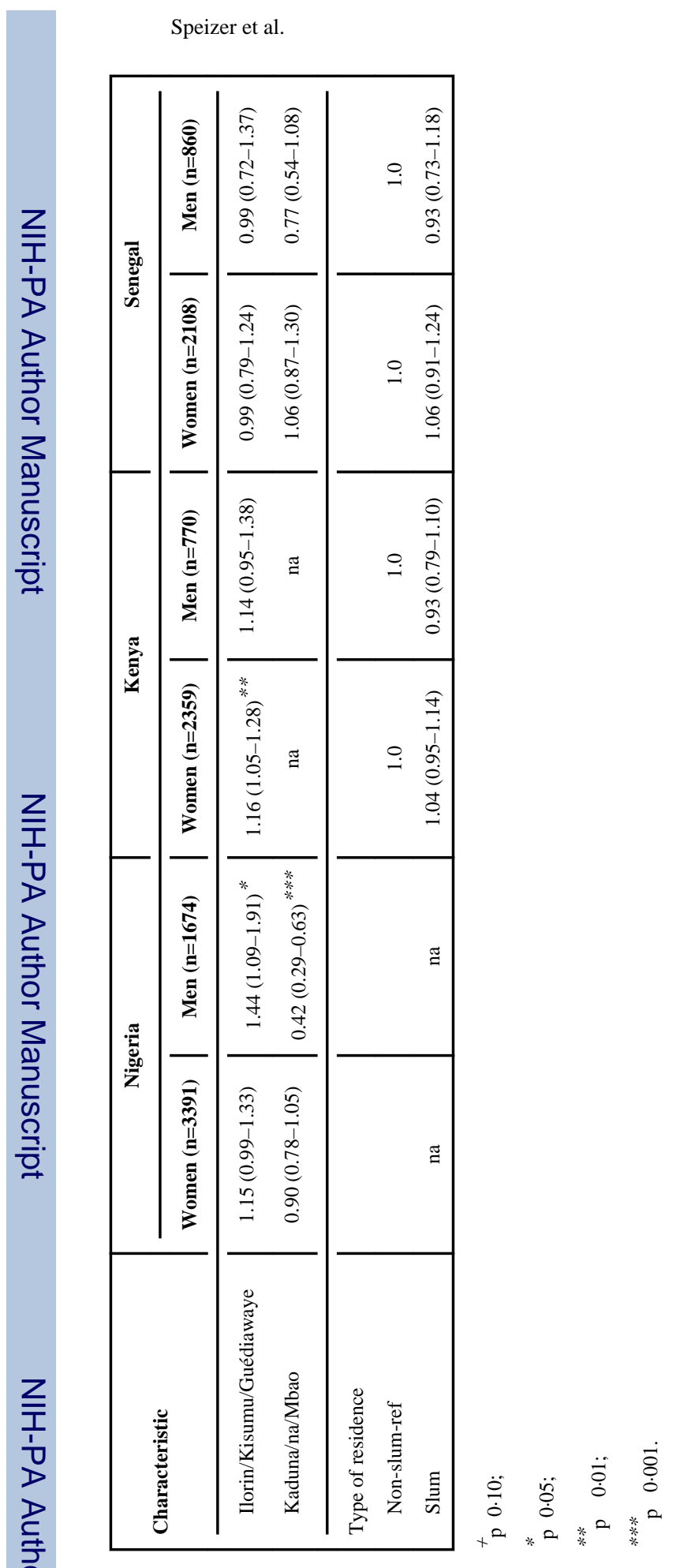


Table 3

Logistic regression odds ratios (and 95\% confidence intervals) for whether first sex was premarital among urban female youth ages 15-24 who ever had sex and are from select cities from Nigeria, Kenya, and Senegal

\begin{tabular}{|c|c|c|c|}
\hline \multirow{2}{*}{ Characteristic } & Nigeria & Kenya & Senegal \\
\hline & Women $(n=1438)$ & Women $(\mathbf{n}=1821)$ & Women $(n=667)$ \\
\hline Age at first sex (continuous) & $0.87(0.82-0.93)^{* * * *}$ & $0.79(0.75-0.83)^{* * * *}$ & $0.81(0.75-0.87)^{* * *}$ \\
\hline \multicolumn{4}{|l|}{ Education } \\
\hline None/Primary - ref & 1.0 & 1.0 & 1.0 \\
\hline Secondary & $3.57(2.57-4.98)^{* * * *}$ & $2.04(1.58-2.62)^{* * *}$ & $1.36(0.89-2.10)$ \\
\hline Higher & $9.84(5.70-17.00)^{* * *}$ & $7.90(4.70-13.29)^{* * *}$ & $1.70(1.02-2.82)^{*}$ \\
\hline \multicolumn{4}{|l|}{ Employment } \\
\hline Working/In school - ref & 1.0 & 1.0 & 1.0 \\
\hline Not working & $1.30(0.97-1.76)^{+}$ & $0.87(0.68-1.10)$ & $2.01(1.22-3.31)^{* *}$ \\
\hline Wealth (Richest - ref) & 1.0 & 1.0 & 1.0 \\
\hline Poorest & $1.49(0.91-2.42)$ & $0.33(0.20-0.54)^{* * * *}$ & $0.97(0.49-1.90)$ \\
\hline Poor & $0.84(0.52-1.34)$ & $0.40(0.24-0.67)^{* * *}$ & $1.13(0.61-2.11)$ \\
\hline Middle & $0.87(0.54-1.40)$ & $0.32(0.19-0.54)^{* * * *}$ & $0.86(0.48-1.54)$ \\
\hline Rich & $1.01(0.63-1.61)$ & $0.33(0.19-0.57)^{* * * *}$ & $0.56(0.27-1.19)$ \\
\hline \multicolumn{4}{|l|}{ Religion } \\
\hline Non-Muslim/Protestant - ref & 1.0 & 1.0 & 1.0 \\
\hline Catholic & 1.0 & $1.26(0.97-1.62)$ & 1.0 \\
\hline Muslim & $0.25(0.17-0.38)^{* * *}$ & $0.37(0.25-0.53)^{* * *}$ & $0.09(0.04-0.20)^{* * *}$ \\
\hline \multicolumn{4}{|l|}{ Duration of residence } \\
\hline 1 year or less & $0.25(0.16-0.40)^{* * *}$ & $0.38(0.19-0.75)^{* *}$ & $0.68(0.38-1.19)$ \\
\hline $2-5$ years & $0.29(0.19-0.45)^{* * *}$ & $0.26(0.13-0.51)^{* * * *}$ & $0.64(0.36-1.14)$ \\
\hline$>5$ years & $0.43(0.25-0.74)^{* *}$ & $0.33(0.15-0.70)^{* *}$ & $0.89(0.49-1.61)$ \\
\hline Always (ref) & 1.0 & 1.0 & 1.0 \\
\hline \multicolumn{4}{|l|}{ City } \\
\hline Abuja/Nairobi/Dakar - ref & 1.0 & 1.0 & 1.0 \\
\hline Ibadan/Mombasa/Pikine & $3.05(1.83-5.09)^{* * *}$ & $0.97(0.73-1.30)$ & $0.48(0.26-0.87)^{*}$ \\
\hline Ilorin/Kisumu/Guédiawaye & $3.15(1.90-5.24)^{* * * *}$ & $1.19(0.88-1.60)$ & $0.85(0.52-1.39)$ \\
\hline Kaduna/na/Mbao & $0.51(0.30-0.85)^{* *}$ & na & $0.58(0.36-0.95)^{*}$ \\
\hline \multicolumn{4}{|l|}{ Type of residence } \\
\hline Non-slum-ref & & 1.0 & 1.0 \\
\hline Slum & na & $0.80(0.62-1.02)^{+}$ & $0.96(0.64-1.45)$ \\
\hline
\end{tabular}




$$
\begin{aligned}
& \left.{ }^{+} \mathrm{p} \unlhd\right) \cdot 10 \text {; } \\
& \text { p s).05; } \\
& \text { p } \leq 0 \cdot 01 \text {; } \\
& \text { *** } \text { p } \$ 0.001
\end{aligned}
$$


(⿸丆口

를

ฮ

플

ีㅠㄹ

ב্工

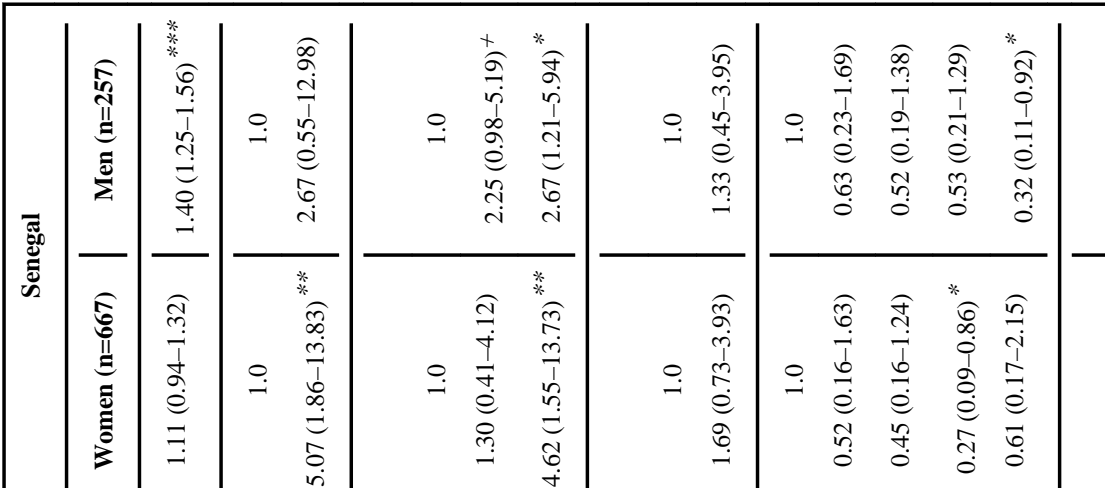

$\vec{D}$

的

:

정

ह

ลิ

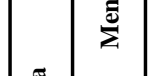

范

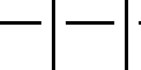

(1)

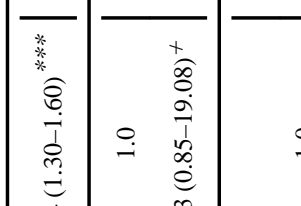

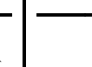

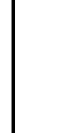

$\stackrel{-}{\circ}$

+ *

के

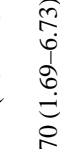

के

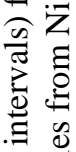

:

造造

छ

을

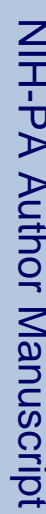

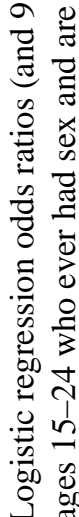

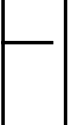

-

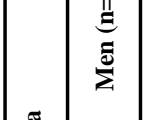

$\stackrel{-}{-}$

$+$

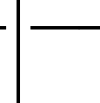

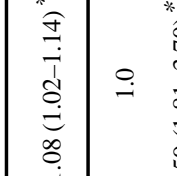

(

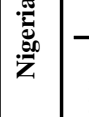

z

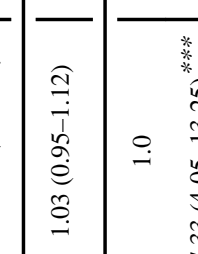

$\stackrel{\circ}{-}$

$\stackrel{2}{\circ}$

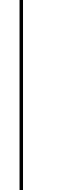

$\stackrel{\circ}{\circ}$

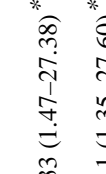

(ब)

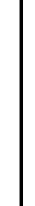

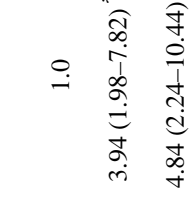

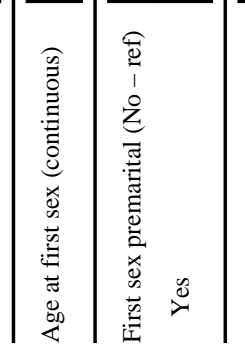

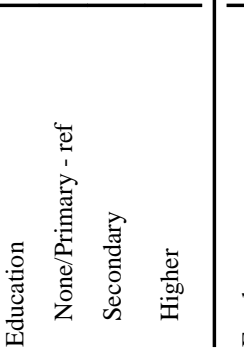

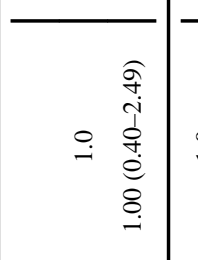

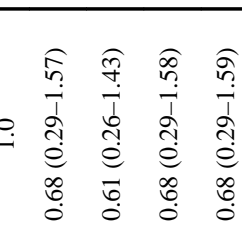

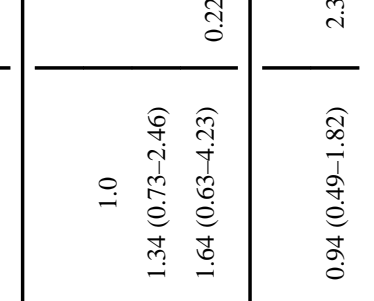

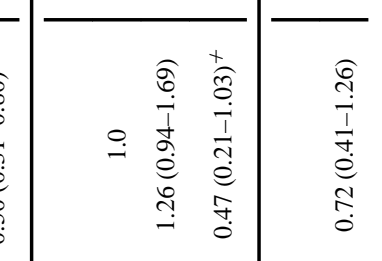

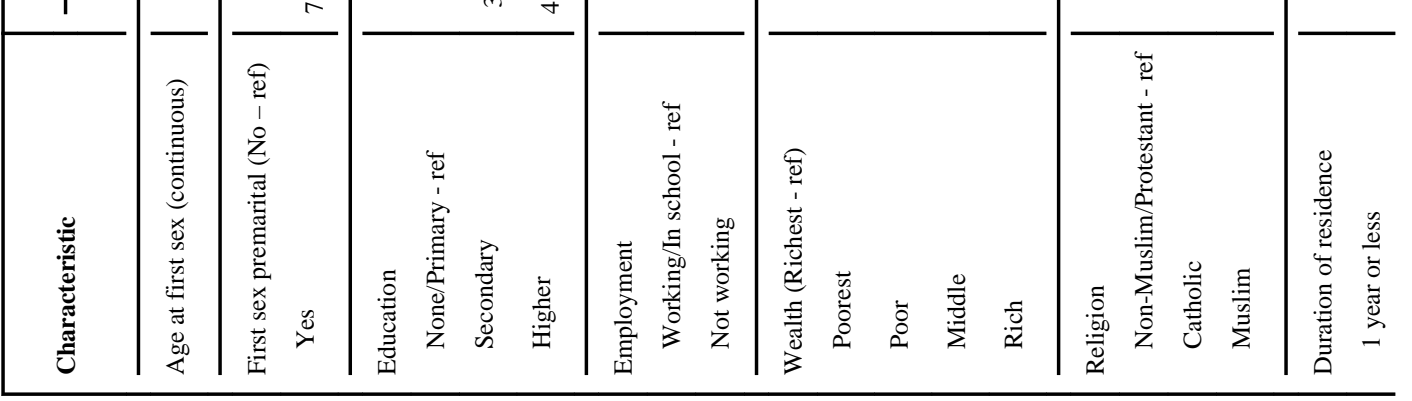




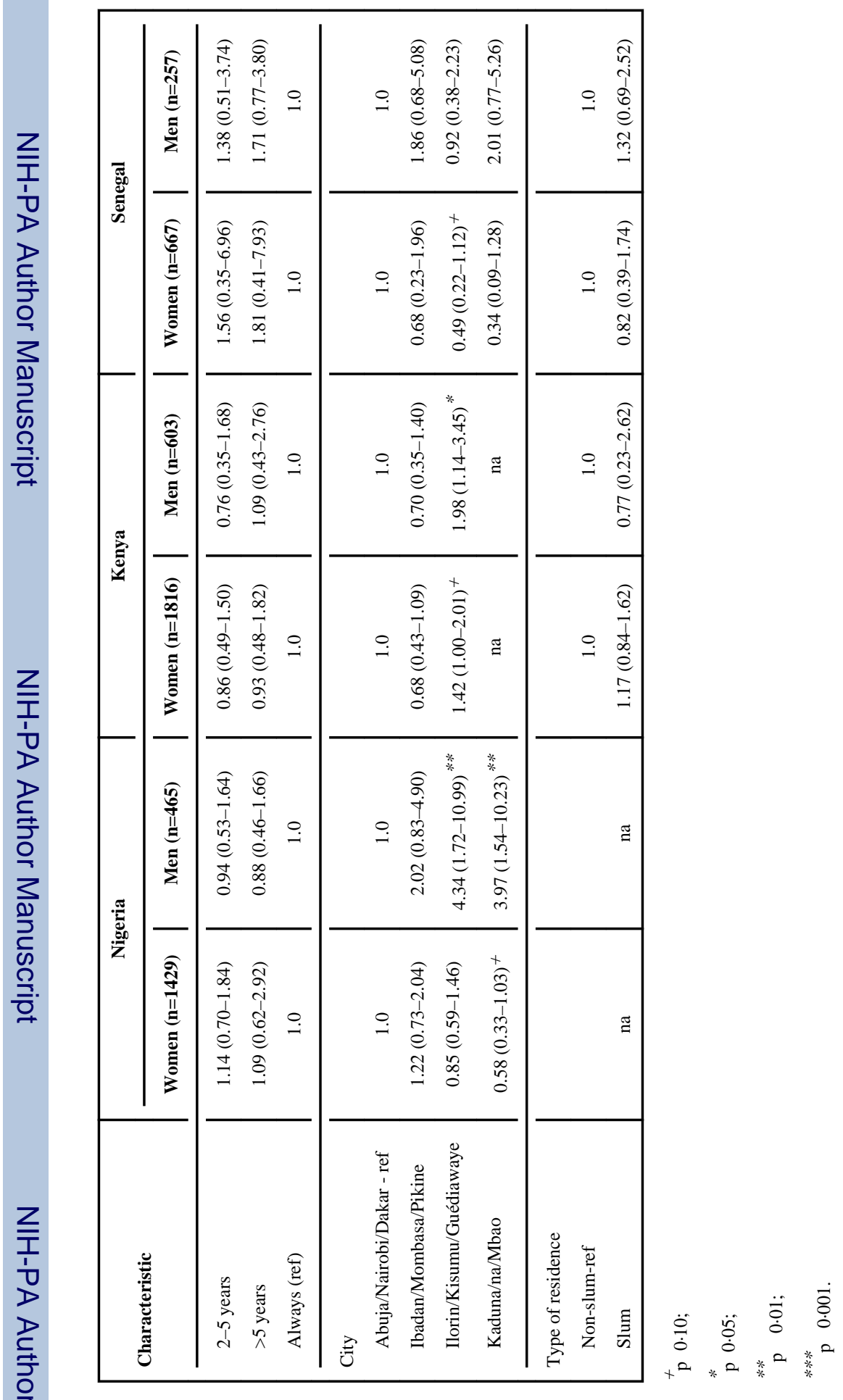

